\title{
Margaret McCartney: Is Jeremy Hunt our colleague?
}

\author{
Margaret McCartney general practitioner, Glasgow
}

When the health secretary, Jeremy Hunt, emailed all junior doctors with his contract proposals, he began, "Dear colleague." So let's consider Hunt as a colleague, a team mate, a coworker, an ally-a doctor.

The NHS's "duty of candour" policy requires doctors to apologise for and reflect on errors that they make. A photograph that Hunt tweeted of himself in a hospital contained identifiable patient information. It was subsequently altered, but there has been no public apology or statement of reflection from the Department of Health.

The General Medical Council takes a dim view of misleading claims. Hunt has promised a "truly seven day NHS." But we already have a seven day NHS. Rather, Hunt seems to be promising an NHS with the same services available on a Sunday at $11 \mathrm{pm}$ as are available on a Tuesday at $10 \mathrm{am}$. The NHS has so far managed to balance staff costs and patient need by doing most routine work in the daytime on weekdays, with weekend and night time staffing for urgent and emergency care. This has meant having more daytime staff to do the routine work as well as the emergency work. Hunt's seven day NHS would need more doctors to do routine and emergency work at nights and weekends, just as in weekday daytimes. With the same total number of doctors, fewer would be available at daytime. If fewer doctors on Saturdays and Sundays do cause a "weekend effect," although that's not been shown, fewer working on weekdays would simply shift an excess mortality to Monday-Friday instead.

Doctors should avoid confusing causation with association. Hunt told the BBC's Today programme on 16 July (www.bbc. co.uk/news/health-33542940) that, because in 2003 the government allowed consultants to say "we're not going to do any work at weekends," patients "admitted on a Sunday ... are $15 \%$ more likely to die than if you are admitted on a Wednesday, and we have 6000 avoidable deaths every year." But no data show how many of these deaths are avoidable.
Doctors have an ethical duty to get their facts right and to reflect evidence fairly. The consultant opt-out was only for non-emergency work and has been used by less than $1 \%$ of consultants. ${ }^{1}$ So this clause is irrelevant to the understaffed emergency care that Hunt says he is concerned about.

Doctors should be honest about the uncertainties of data and should work to reduce them. This should mean doing high quality research into weekend versus weekday care to decide what needs investment, be it hospital beds, radiographers, nurses, porters, or doctors.

Hunt is not a colleague. He is a threat to the stability and ethos of the NHS.

Competing interests: I have read and understood the BMJ policy on declaration of interests and declare the following interests: I'm an NHS GP partner, with income partly dependent on Quality and Outcomes Framework points. I'm a part time undergraduate tutor at the University of Glasgow. I've written two books and earn from broadcast and written freelance journalism. I'm an unpaid patron of Healthwatch. I make a monthly donation to Keep Our NHS Public. I'm a member of Medact. I'm occasionally paid for time, travel, and accommodation to give talks or have locum fees paid to allow me to give talks but never for any drug or public relations company. I was elected to the national council of the Royal College of General Practitioners in 2013 and am chair of its standing group on overdiagnosis. I have invested a small amount of money in a social enterprise, Who Made Your Pants?

Provenance and peer review: Commissioned; not externally peer reviewed.

Follow Margaret on Twitter, @mgtmccartney

Rimmer A. $1 \%$ of consultants have opted out of weekend working. BMJ Careers 4 Sep 2015. http://careers.bmj.com/careers/advice/1\%2525 of consultants have_opted_out of_elective_weekend_working.

Cite this as: BMJ 2015;351:h5995

๑ BMJ Publishing Group Ltd 2015 